Earth and Planctary Science Letters, 28 (1975) $23-32$

(C) Elsevier Scientific Publishing Company, Amsterdam - Printed in The Netherlands

\title{
GLOBAL HEAT FLOW: A NEW LOOK
}

\author{
DAVID S. CHAPMAN* and HENRY N. POLLACK \\ Department of Geology and Mineralogy, The University of Michigan, Ann Arbor, Mich. (USA)
}

Received June 19,1975

Revised version received August 11, 1975

\begin{abstract}
A global heat flow map has been derived from existing observations supplemented in areas without data by an empirical predictor based on tectonic setting and age. In continental areas the predictor is based on the observed correlation of heat flow with age of last tectono-thermal event, and in oceanic regions on the observed relation of heat flow to age of ocean floor. The predictor was used to assign mean heat flow values to $5^{\circ} \times 5^{\circ}$ grid areas on the globe, weighted according to the relative area of tectonic provinces represented. A spherical harmonic analysis to degree 12 of the heat flow field yields a mean value of $59 \mathrm{~mW} \mathrm{~m}^{-2}$, a $\mathrm{rms}$ residual of $13 \mathrm{~mW} \mathrm{~m}^{-2}$, and an amplitude spectrum which decreases gradually and almost monotonically from $n=1$. The spherical harmonic representation of the heat flow field is free of the unreal distortions which have characterized earlier analyses based on a geographically sparse data set. Areas with residuals greater than $15 \mathrm{~mW} \mathrm{~m}^{-2}$ comprise less than $19 \%$ of the area of the globe, thus indicating that most heat tlow provinces have characteristic dimensions adequately represented in a 12 -degree analysis.
\end{abstract}

\section{Introduction}

The heat conducted to the surface of the earth from its interior averages about $60 \mathrm{~mW} \mathrm{~m}$, and most of the regional variation in the heat flux lies within a factor of three about the mean. Our present knowledge of the regional distribution of the heat flux, and its relationship to tectonic elements certainly must rank among the significant geophysical achievements of the past decade. The principal uses of the heat flow data are in estimating temperatures at shallow depths within the earth, and in serving as a boundary constraint on models of geodynamic processes.

It is convenient to have a functional representation of the surface heat flow, which for data distributed over the globe is most commonly in terms of surface spherical harmonic functions. Spherical harmonic analyses of global heat flow have been reported every few years in progressively greater detail as the data set has grown. In 1963, Lee and MacDonald [1] reported coefficients to degree 2 based on 813 observations; in

\footnotetext{
* Present address: Department of Natural Sciences, University of Michigan-Dearborn, Dearborn, Michigan, U.S.A.
}

1965, Lee and Uyeda [2] calculated coefficients to degree 3 from 1162 values; and in 1969, Horai and Simmons [3] used 2812 existing observations to calculate coefficients to degree 7 .

Unfortunately all these previous analyses of the existing measurements have been characterized by unreal distortions in the harmonic representation of the heat flow field, caused by lack of observations in several critical areas. A notable example of these distortions was the "African bubble", a broad heat

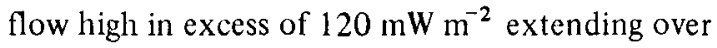
much of North Africa, which was a consequence of a few very high observations in the Red Sea, and lack of data to constrain the functions over much of Africa and the Middle East. Lesser but equally improbable features of these previous representations include: a broad high in excess of $100 \mathrm{~mW} \mathrm{~m}^{-2}$ in east Asia, unconstrained by lack of data between Lake Baikal and the Japan Sea; a high of $120 \mathrm{~mW} \mathrm{~m}^{-2}$ in the Precambrian of East Antarctica where no data exist; and zero or negative heat flow in the South Pacific near Antarctica, also where no data exist. These distortions arise from attempts to find a global expression for a geographically sparse data set. Even at 
the time of the Horai and Simmons [3] analysis, data were available for only 710 of the $25925^{\circ} X$ $5^{\circ}$ grid areas on the globe, and one third of these were represented by a single measurement. Furthermore, there was extremely poor coverage for most of Africa, South America, Antarctica, and the highlatitude oceans.

The problems associated with the spherical harmonic analysis of a sparse data set may be overcome in two ways: by improving the coverage with measurements in the unrepresented regions; or alternatively, by predicting heat flow in the unsampled regions, thereby creating a synthetic supplement to the existing observations. The former solution will certainly be slow, and in continental areas, an increasingly difficult task. However, a sufficiently adequate understanding of the underlying causes of regional variation in heat flow has now been achieved to make the second solution reasonable. In particular the recognition that continental heat flow is correlated with age of last tectono-thermal mobilization [4], and oceanic heat flow with the age of the ocean floor [5], makes it now possible to use prediction methods with existing tectonic and geologic maps to estimate with considerable confidence mean heat flows for all unsurveyed $5^{\circ} \times 5^{\circ}$ regions.

In this paper we describe an empirical heat flow predictor which is used to supplement existing observations to create a fyll global heat flow data set, and the spherical harmonic analysis of the surface heat flow field thereby obtained.

\section{Empirical heat flow predictor}

The basis of our heat flow predictor is the correlation of heat flow with tectonic setting. For continents we follow the example of Polyak and Smirnov [4] who recognized that subsets of continental heat flow observations based on age of latest tectono-thermal event are normally distributed about the mean heat flow of that subset and that heat flow decreases from younger to older tectonic elements. Fig. 1 (top) shows the general decrease of continental heat flow with increasing age. We have constructed individual continental predictors from existing heat flow data [6] for North America, Europe west of the Scythian fault, Asia, and Australia. The parameters of these predictors

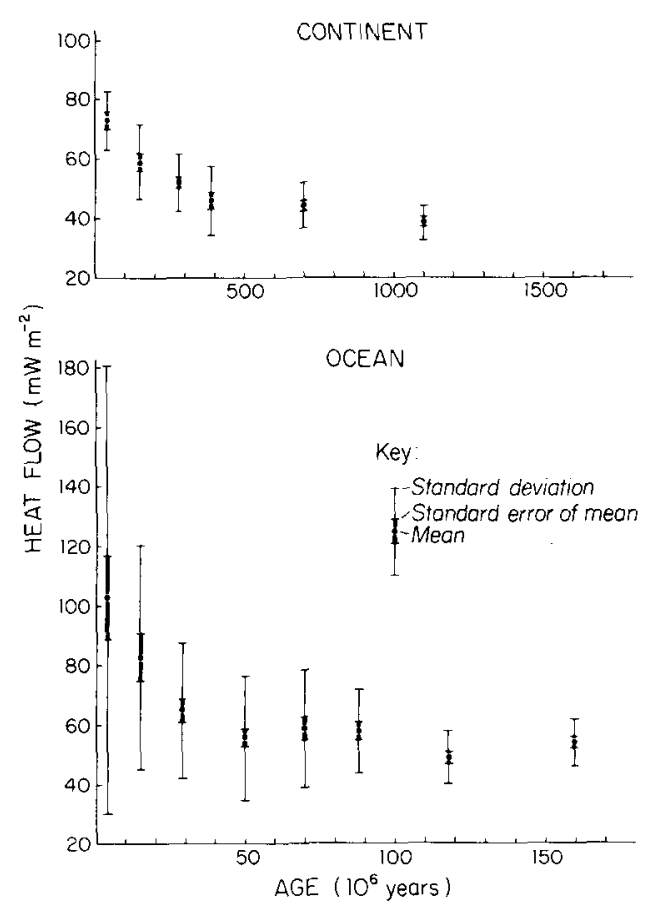

Fig. 1. Top: mean heat flow versus age of tectono-thermal province for continents, after Polyak and Smirnov [4]. Bottom: mean heat flow versus age of ocean floor for typical ocean. Length of bold bar gives magnitude of the standard error of the mean; thin bar gives standard deviation.

are tabulated in Table 1. For Africa, Antarctica and South America there is insufficient observational data on which to base an individual continental predictor, and so the general parameters of Polyak and Smirnov (Table 1) are used. The discrepancies between tectonic province average heat flow for different continents and the Polyak-Smirnov values, most serious for the Paleozoic and Mesozoic, suggest that the Polyak and Smirnov analysis [4] requires updating. However, the use of predictor values based on their analysis will not lead to serious errors in Africa, Antarctica, or South America, all of which have large tracts of Precambrian terrane.

Predictors for oceanic regions were based on the general decrease of heat flow with age of ocean floor illustrated in Fig. 1 (bottom). Regional oceanic predictors were used for the North Pacific, South Atlantic, and Indian Oceans and a "typical ocean" predictor, based on mean values, used elsewhere. The param eters for each region are given in Table 2. 
TABLE 1

Continental heat flow

\begin{tabular}{|c|c|c|c|c|c|}
\hline \multirow[t]{2}{*}{ Tectonic province } & \multicolumn{5}{|c|}{ Heat flow $\left(\mathrm{mW} \mathrm{m}^{-2}\right)$} \\
\hline & N. America [6] & Australia [6] & Europe [6] & Asia [6] & Typical continent $[4]$ \\
\hline Archean shield & 41 & 43 & & 36 & \multirow{2}{*}{38} \\
\hline Proterozoic shield & 55 & 73 & 38 & 45 & \\
\hline Precambrian platform & 49 & & & & 44 \\
\hline Phanerozoic non-orogenic & 53 & 61 & 72 & 45 & \\
\hline Caledonian orogeny & 48 & 85 & 65 & & 46 \\
\hline Hercynian orogeny & 62 & 58 & 67 & 56 & 52 \\
\hline Mesozoic orogeny & 80 & & & 73 & 59 \\
\hline \multicolumn{6}{|l|}{ Cenozoic } \\
\hline intermontane trough & & & & & 41 \\
\hline folding & 75 & 80 & 78 & 63 & 73 \\
\hline volcanism & & & & & 92 \\
\hline
\end{tabular}

For each $5^{\circ} \times 5^{\circ}$ grid element on the globe, estimates were made of the fraction (to the nearest 5\%) of the element represented by each tectono-thermal province, and/or oceanic age group present. The estimates were made visually from the maps and references listed in the Appendix. Mean heat flow values were then computed for each element using the appropriate predictor, weighted with respect to the area of each province present.

Three examples will serve to illustrate the application of our heat flow predictor methods. In the simplest case a single tectonic province is represented in a $5^{\circ} \times 5^{\circ}$ area. The predicted heat flow is then the rep- resentative value for that tectonic province, and in general will be found to be in good agreement with the observational mean, providing the latter is well established. Such is the case for the element located at $50^{\circ}$ to $55^{\circ} \mathrm{N}$ and $35^{\circ}$ to $40^{\circ} \mathrm{E}$ which is comprised only of Russian platform, and for which the predicted heat flow and the mean of 14 observations are both $45 \mathrm{~mW} \mathrm{~m}^{-2}$.

The second example is drawn from $5^{\circ} \times 5^{\circ}$ elements comprised of more than one tectonic province, for which the distribution of observations is widespread. Fig. 2 shows such an example from eastern North America. We estimate the element to be com-

TABLE 2

Oceanic heat flow

\begin{tabular}{|c|c|c|c|c|c|}
\hline \multirow[t]{2}{*}{ Tectonic province } & \multirow[t]{2}{*}{ Age $(\mathrm{Myr})$} & \multicolumn{4}{|c|}{ Heat flow $\left(\mathrm{mW} \mathrm{m}^{-2}\right)$} \\
\hline & & N. Pacific [5] & S. Atlantic [5] & Indian [7] & Typical ocean \\
\hline Jurassic & $>136$ & 54 & & & \\
\hline Early Cret. & $100-136$ & 49 & 48 & & 49 \\
\hline Mid Cret. & $76-100$ & 58 & 59 & 53 & 58 \\
\hline Late Cret. & $63-76$ & 60 & 59 & & 59 \\
\hline Anom. 13-25 & $38-63$ & 60 & 53 & 55 & 56 \\
\hline Anom. $6-13$ & $20-38$ & 67 & 29 & & 65 \\
\hline Anom. $5-6$ & $10-20$ & 93 & 73 & 64 & 83 \\
\hline Anom. $0-5$ & $0-10$ & 118 & 90 & 100 & 103 \\
\hline
\end{tabular}



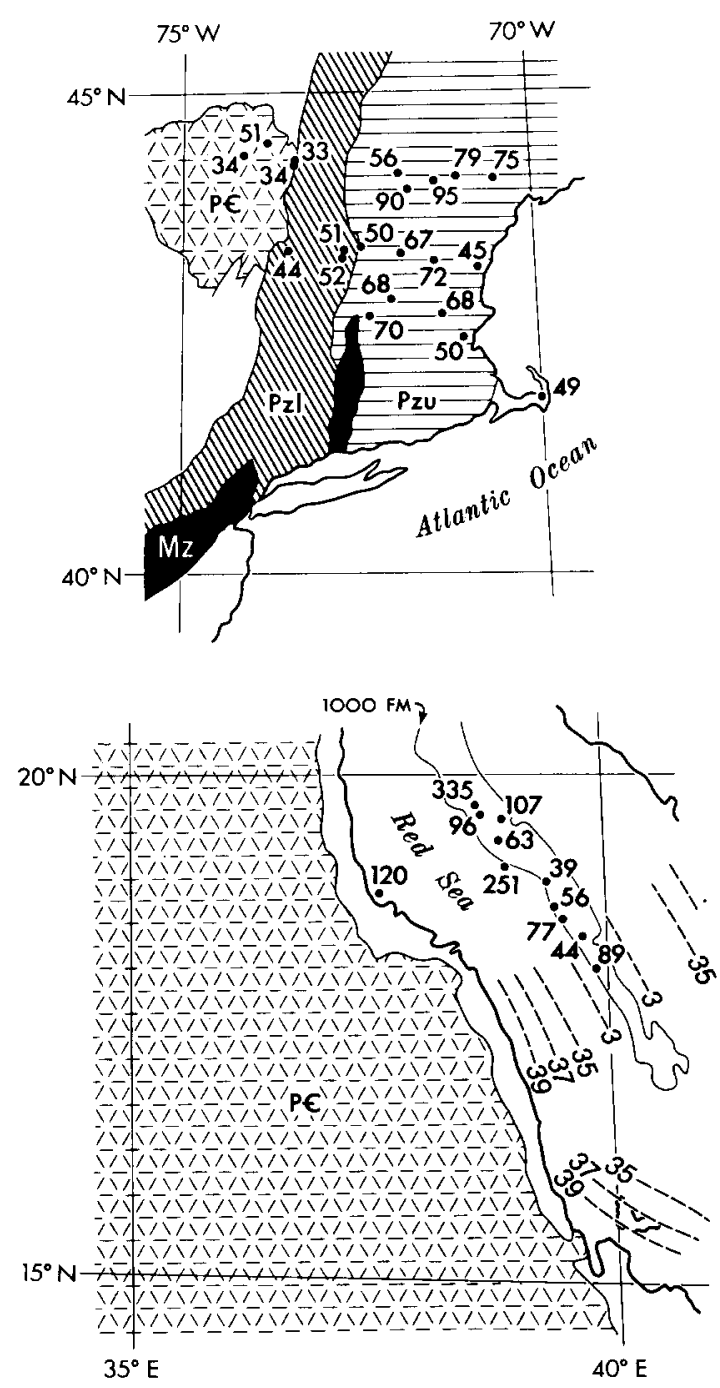

Fig. 2. Examples of $5^{\circ} \times 5^{\circ}$ elements showing distribution of tectonic provinces and heat flow sites. Top: grid element from northeast United States for which heat flow sites are widely distributed within the element. Bottom: grid element from Red Sea where heat flow locations are unrepresentative of entire element. Ocean floor isochrons in $10^{6}$ years from Girdler and Styles [8]. Heat flow in $\mathrm{mW} \mathrm{m}^{-2}$.

prised of the following provinces: Precambrian shield $10 \%$; Phanerozoic non-orogenic (including foreland, coastal plain and shelf), 35\%; Caledonian orogeny, $20 \%$; Hercynian orogeny, $30 \%$ and Mesozoic orogeny, $5 \%$. Using the North American values given in Table 2 for these provinces, the predicted heat flow for this grid element is $56 \mathrm{~mW} \mathrm{~m}^{-2}$, in close agreement with the mean value of $59 \mathrm{~mW} \mathrm{~m}^{-2}$ for the 21 reported observations.

The final example is drawn from $5^{\circ} \times 5^{\circ}$ elements which are again comprised of more than one tectonic province, but where the tectonic setting of the measurement sites are not generally representative of the grid element. An extreme case is the Red Sea region shown in Fig. 2. The grid element was divided into the following provinces by using the tectonic map of Africa (see Appendix) for the continental area, and Girdler and Styles' [8] spreading history for the Red Sea: Precambrian shield, 70\%; oceanic crust, anomaly $13-25$ (38-63 Myr), 10\%; anomaly $6-13$, (20-38 Myr), 10\%; anomaly 0-5 (0-10 Myr), $10 \%$. The predicted heat flow calculated from these fractions is $63 \mathrm{~mW} \mathrm{~m}^{-2}$, in contrast to $117 \mathrm{~mW} \mathrm{~m}^{-2}$, the mean of the 11 observations shown. This dis-

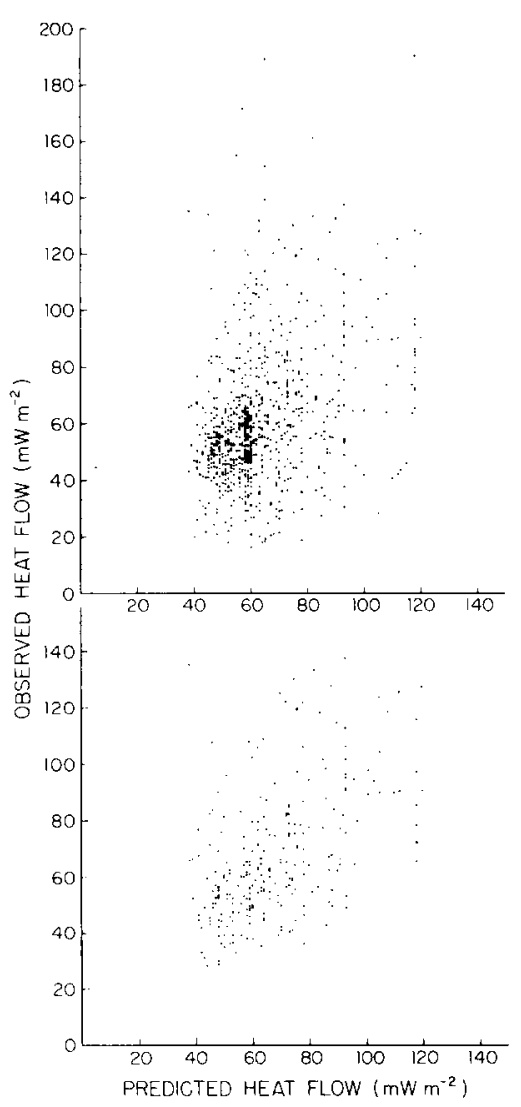

Fig. 3. Comparison of predicted heat flow with mean observed heat flow for $5^{\circ} \times 5^{\circ}$ elements. Top: for the 829 elements where one or more observations exist. Bottom: for the 260 elements where 5 or more observations exist. 


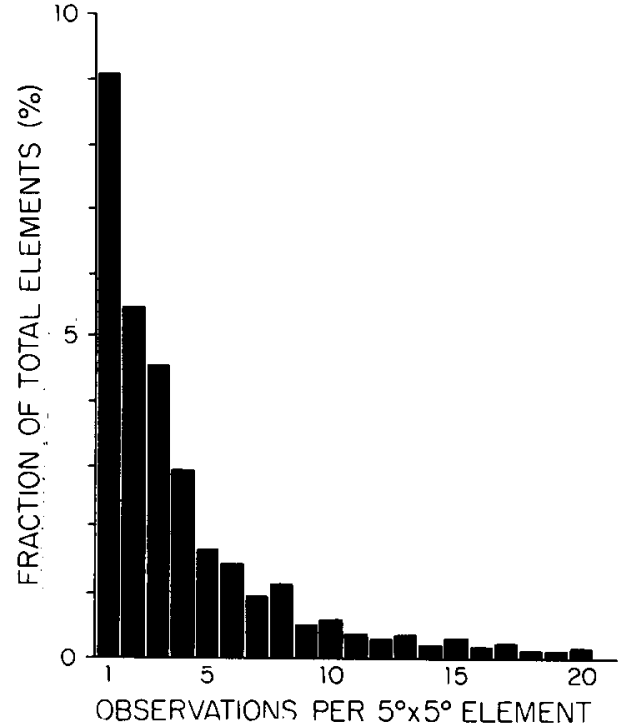

Fig. 4. Histogram of $5^{-} \times 5^{-}$heat flow measurement populations. $68 \%$ of total elements have no observations; $1 \%$ of total elements have more than 20 observations.

crepancy arises because the actual heat flow site distribution is clearly unrepresentative of the whole element; ten of the eleven sites lie within the anomaly $0-5$ province, while this province represents only $10 \%$ of the grid element.

Predicted heat flow values have been computed for all $25925^{\circ} \times 5^{\circ}$ elements and compared to $5^{\circ} \times$ $5^{\circ}$ observational means wherever observations exist. The comparison is shown in Fig. 3 for the 829 elements with at least one measurement and for the 260 elements witn 5 or more observations. Large differences bet'veen predicted and observed heat flow can be expected if there is only one or a small number of observations in the element (see magnitude of standard deviation for individual province heat flow, Fig. 1), or if the measurements are unrepresentative of the tectonic composition of the element. Fig. 4 is a histogram of density of observations per $5^{\circ} \times 5^{\circ}$ element and illustrates the preponderance of poorly populated elements within the global heat flow data set. Regression correlations of predicted versus observed heat flow have been computed for several truncated data sets, with progressively higher minimum population cutoffs; agreement between prediction and observation improves consistently with increasing number of observations per element. In the next section we present the spherical harmonic analyses of the two heat flow data sets: the predicted heat flow alone; and the observed heat flow supplemented by predicted values in grid elements where no observations exist.

\section{Spherical harmonic analysis}

Each data set subjected to analysis comprises mean heat flow, observed or predicted, for all $5^{\circ} X$ $5^{\circ}$ elements on the surface of the globe. The spatial distribution of elements represented by observations, and which therefore contribute to the supplemented data set, is shown in Fig. 5. The 829 elements with at least one measurement, constitute $42 \%$ of the surface area of the globe, but are unevenly distributed. Both data sets have been represented by a spherical harmonic expansion of the form:

$$
\begin{aligned}
q(\theta, \phi) & =\sum_{n=0}^{N} \sum_{m=0}^{n}\left[A_{n m} \cos (m \phi)\right. \\
& \left.+B_{n m} \sin (m \phi)\right] P_{n m}(\cos \theta)
\end{aligned}
$$

where $q$ is the heat flow field, $\theta$ is colatitude, $\phi$ is longitude, $A_{n m}$ and $B_{n m}$ the coefficients of the expansion, and $\boldsymbol{P}_{n \boldsymbol{m}}$ the associated Legendre functions, fully normalized so that:

$\int_{0}^{2 \pi} \int_{0}^{\pi}\left[P_{n m}(\cos \theta){ }_{\cos }^{\sin }(m \phi)\right]^{2} \sin \theta \mathrm{d} \theta \mathrm{d} \phi=4 \pi$

The spherical harmonic coefficients $A_{n m}$ and $B_{n m}$ up to degree $n=12$ were calculated by numerical integration from:

$$
\begin{aligned}
& A_{n m}=\frac{1}{4 \pi} \int_{0}^{2 \pi} \int_{0}^{\pi} \bar{q}(\theta, \phi) \underset{\sin (m \phi)}{\cos (m \phi)} \times P_{n m}(\cos \theta) \\
& B_{n m} \cdot \sin \theta \mathrm{d} \theta \mathrm{d} \phi
\end{aligned}
$$

and are given in Table $3 . \bar{q}$ in (3) is the $5^{\circ} \times 5^{\circ}$ mean heat flow.

\section{The new heat flow field}

The degree 12 heat flow fields derived from analy. sis of the predicted data set and the observations plus predictor data sets are shown in Figs. 6 and 7 respectively. The most important characteristics of both 


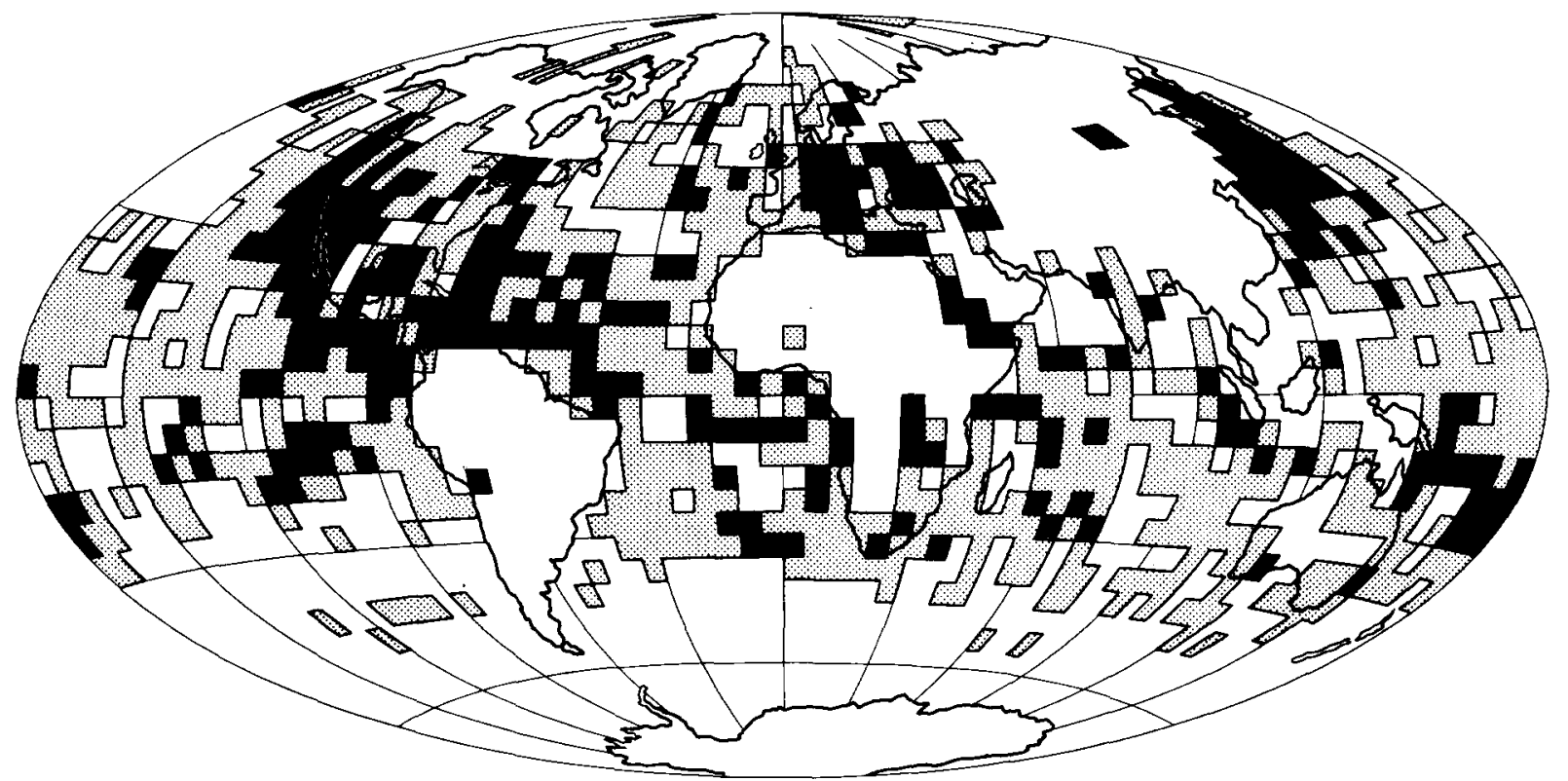

Fig. 5. Distribution of global heat flow data. Dot pattern indicates 1 to 4 observations in $5^{\circ} \times 5^{\circ}$ element; solid pattern indicates 5 or more observations in $5^{\circ} \times 5^{\circ}$ element. Aitoff-Hammer projection.

new representations are the excellent delineation of the features of the heat flow field already established from measurements, and the elimination of unrealistic distortions in regions where no observations exist.

All the major oceanic ridge systems are represented as heat flow highs, as are the marginal basins of the West Pacific, Alpine Europe, and the American Cordillera. The Galapagos spreading center and the Chile Rise appear as bulges on the East Pacific Rise pattern. Low heat flow regions include all the major shields and platforms, and the oldest oceanic regions. The West Australian low includes both the YilgarnPilbara shield and part of the mid-Cretaceous Wharton basin.

The difference between the reconstructed fields in Fig. 6 and 7 are slight. Heat flow observations in both the Red Sea-Gulf of Aden and Gulf of California regions are dominated by spatially restricted but abnormally high heat flow settings, and therefore appear in Fig. 7 as accentuated highs. The same provinces have much smaller effect when subjected to the predictor weighting procedure. In Fig. 7 the East Pacific Rise pattern is modified slightly. The southern Africa low is eliminated due to above normal heat flow observed in the central African shield [9].
The mean values of 61 and $59 \mathrm{~mW} \mathrm{~m}^{-2}$ for the predicted and observed plus predicted heat flow fields respectively, are comparable to earlier estimates for the mean global heat flow $[3,10]$. The rms residual between the degree 12 reconstructions and the input data sets are 8 and $13 \mathrm{~mW} \mathrm{~m}^{-2}$ respectively. Areas with residuals greater than $15 \mathrm{~mW} \mathrm{~m}^{-2}$ comprise less than $19 \%$ of the area of the globe in both representations, thus indicating that most heat flow provinces have characteristic dimensions adequately represented in a degree 12 analysis. Those regions with larger residuals are recognized to be regions where strongly contrasting tectonic provinces lie in close proximity, such as the old ocean basin-island arc transitions in the western Pacific, and the ocean ridge-stable continent transitions in the vicinity of the Arabian Peninsula, Greenland, and western North America. Large residuals may also arise in regions where the general heat flow-age relationships do not apply, such as recent subduction zones [11] or areas of incipient rifting [9].

The mean value of the heat flow field represented by all harmonics of degree $n$, calculated from:

$\left[\sum_{m=0}^{n}\left(A_{n m}^{2}+B_{n m}^{2}\right)\right]^{1 / 2}$ 


\section{GLOBAL HEAT FLOW}
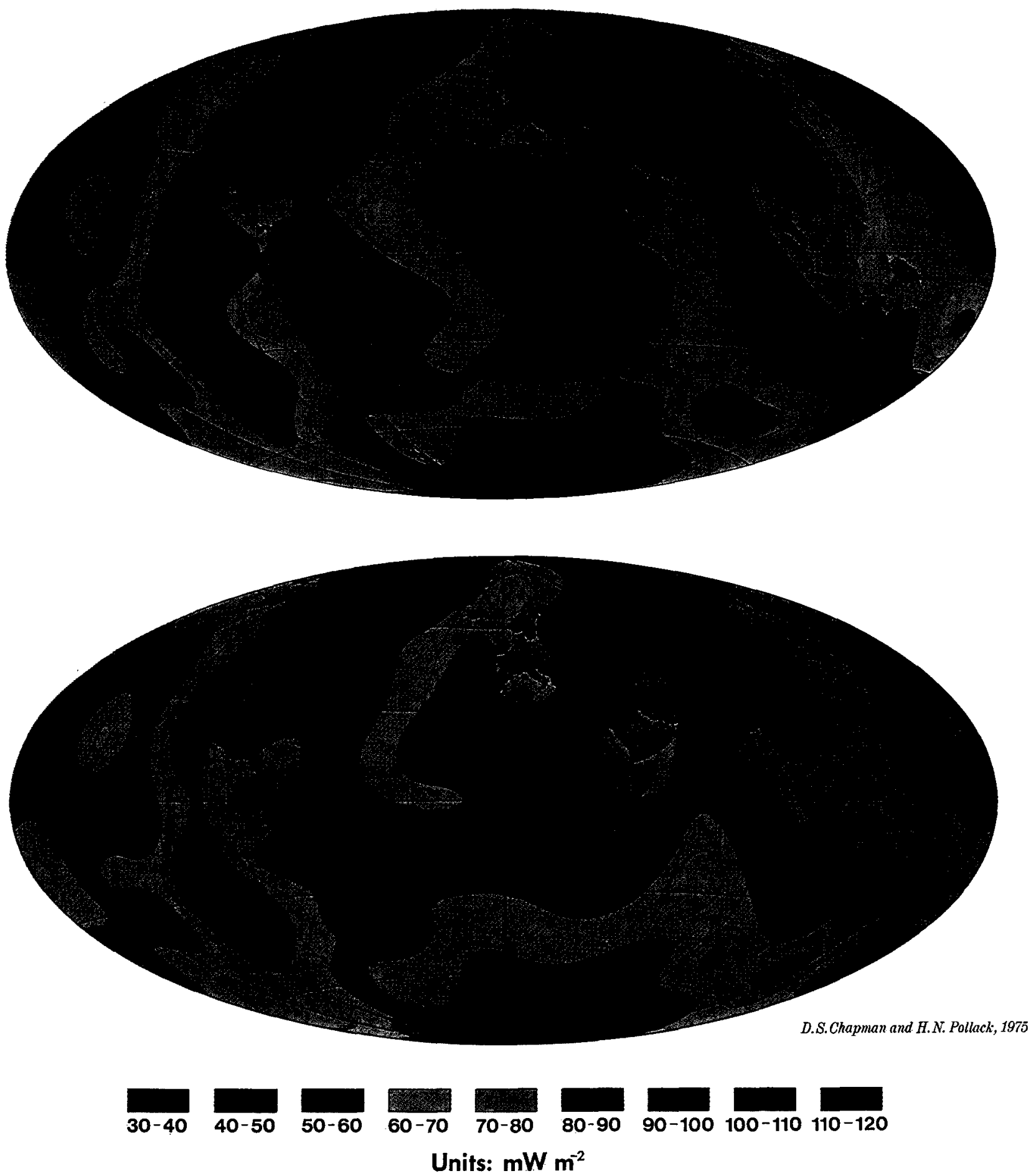

Fig. 6 (top). Degree 12 spherical harmonic representation of global heat flow from predictor method only.

Fig. 7 (bottom). Degree 12 spherical harmonic representation of global heat flow from observations supplemented by predictor. 
TABLE 3

Fully normalized spherical harmonic coefficients of terrestrial heat flow in units of $\mathrm{mW} \mathrm{m}^{-2}$

\begin{tabular}{|c|c|c|c|c|c|c|c|c|c|c|c|}
\hline \multirow[t]{2}{*}{$n$} & \multirow[t]{2}{*}{$m$} & \multicolumn{2}{|c|}{ Predicted } & \multicolumn{2}{|c|}{ Observed + predicted } & \multirow[t]{2}{*}{$n$} & \multirow[t]{2}{*}{$m$} & \multicolumn{2}{|c|}{ Predicted } & \multicolumn{2}{|c|}{ Observed + predicted } \\
\hline & & $A_{n m}$ & $B_{n m}$ & $A_{n m}$ & $B_{n m}$ & & & $A_{n m}$ & $B_{n m}$ & $A_{n m}$ & $B_{n m}$ \\
\hline 0 & 0 & 60.529 & & 59.211 & & 9 & 0 & 0.186 & & 0.568 & \\
\hline 1 & 0 & -1.582 & & -1.662 & & 9 & 1 & 1.434 & 0.159 & 1.651 & -0.128 \\
\hline 1 & 1 & -3.539 & -3.276 & -2.973 & -1.373 & 9 & 2 & 0.060 & -0.248 & 0.387 & -0.103 \\
\hline 2 & 0 & -1.794 & & -0.472 & & 9 & 3 & -1.381 & -0.867 & -1.074 & -0.742 \\
\hline 2 & 1 & 1.373 & 0.720 & 0.997 & 0.788 & 9 & 4 & 0.286 & -0.577 & 0.101 & -0.492 \\
\hline 2 & 2 & -4.030 & 1.521 & -3.031 & 1.396 & 9 & 5 & -0.012 & -0.158 & 0.461 & -0.055 \\
\hline 3 & 0 & 0.861 & & 1.415 & & 9 & 6 & 1.074 & -0.146 & 1.070 & 0.926 \\
\hline 3 & 1 & 0.056 & 0.311 & -0.479 & -0.768 & 9 & 7 & -0.517 & -1.209 & 0.208 & -1.247 \\
\hline 3 & 2 & 2.024 & -1.067 & 0.945 & -0.595 & 9 & 8 & 0.884 & 0.661 & 0.342 & 0.159 \\
\hline 3 & 3 & 3.151 & 1.576 & 2.004 & 1.924 & 9 & 9 & 0.160 & 1.110 & 0.769 & 1.607 \\
\hline 4 & 0 & -1.580 & & -2.034 & & 10 & 0 & 0.481 & & 0.468 & \\
\hline 4 & 1 & -0.096 & 0.085 & 0.328 & 0.428 & 10 & 1 & 1.084 & 0.111 & 0.577 & 0.211 \\
\hline 4 & 2 & 1.892 & 0.380 & 1.204 & 0.853 & 10 & 2 & -0.428 & 0.556 & -0.118 & 0.139 \\
\hline 4 & 3 & -1.002 & -0.851 & -0.269 & -1.338 & 10 & 3 & 0.761 & 0.172 & 0.835 & 0.058 \\
\hline 4 & 4 & 0.455 & -4.736 & 0.351 & -2.876 & 10 & 4 & -0.819 & -0.149 & -0.881 & 0.224 \\
\hline 5 & 0 & 1.269 & & 1.540 & & 10 & 5 & 0.134 & 0.102 & 0.018 & 0.162 \\
\hline 5 & 1 & -1.477 & -0.765 & -0.340 & -0.224 & 10 & 6 & -0.859 & -0.237 & -0.633 & 0.152 \\
\hline 5 & 2 & 2.044 & 0.797 & 2.163 & 0.117 & 10 & 7 & -1.038 & 0.424 & -0.600 & 0.470 \\
\hline 5 & 3 & 1.172 & -0.851 & 1.791 & -0.167 & 10 & 8 & 0.109 & 0.415 & -0.258 & 0.386 \\
\hline 5 & 4 & -2.811 & 1.680 & -2.595 & 1.363 & 10 & 9 & 0.048 & 0.241 & 1.261 & 1.036 \\
\hline 5 & 5 & -1.586 & -1.949 & -1.473 & -1.797 & 10 & 10 & 1.074 & -0.864 & 0.769 & -0.832 \\
\hline 6 & 0 & -1.721 & & -0.891 & & 11 & 0 & -0.484 & & -0.463 & \\
\hline 6 & 1 & 0.706 & 1.235 & 1.213 & 0.842 & 11 & 1 & -0.285 & 0.225 & -0.391 & 0.647 \\
\hline 6 & 2 & 1.418 & -0.898 & 2.088 & -1.637 & 11 & 2 & 0.415 & 0.203 & 0.262 & -0.045 \\
\hline 6 & 3 & -0.021 & -0.252 & -0.018 & -0.118 & 11 & 3 & -0.538 & 0.080 & 0.110 & 0.115 \\
\hline 6 & 4 & -0.661 & -0.140 & -0.850 & -1.736 & 11 & 4 & 0.507 & -0.442 & 0.116 & -0.505 \\
\hline 6 & 5 & -0.069 & 0.536 & -0.354 & 0.296 & 11 & 5 & -0.078 & 1.200 & -0.342 & 1.099 \\
\hline 6 & 6 & 0.438 & 1.940 & 0.156 & 1.330 & 11 & 6 & -0.313 & 0.007 & 0.205 & -0.235 \\
\hline 7 & 0 & 0.703 & & 0.087 & & 11 & 7 & -0.228 & -0.007 & 0.182 & -0.126 \\
\hline 7 & 1 & -0.172 & -0.759 & -0.419 & -0.792 & 11 & 8 & 0.388 & 0.255 & 0.566 & 0.705 \\
\hline 7 & 2 & -1.203 & -0.009 & -0.554 & 0.576 & 11 & 9 & 0.144 & 0.978 & -0.139 & 1.501 \\
\hline 7 & 3 & 1.302 & -0.201 & 1.001 & -0.413 & 11 & 10 & -0.123 & 0.124 & 0.128 & -0.029 \\
\hline 7 & 4 & 0.667 & -0.710 & 0.484 & -0.652 & 11 & 11 & -0.113 & -0.406 & -0.207 & -0.605 \\
\hline 7 & 5 & 0.211 & 1.055 & -0.025 & 0.904 & 12 & 0 & 0.122 & & 0.310 & \\
\hline 7 & 6 & -0.859 & 0.275 & 0.269 & -0.280 & 12 & 1 & -0.074 & -0.162 & 0.206 & -0.039 \\
\hline 7 & 7 & 0.580 & -0.272 & 0.050 & -0.217 & 12 & 2 & -0.089 & 0.257 & 0.199 & 0.397 \\
\hline 8 & 0 & 0.848 & & 0.062 & & 12 & 3 & 0.657 & -0.002 & 0.686 & -0.099 \\
\hline 8 & 1 & -0.152 & 1.433 & 0.140 & 1.571 & 12 & 4 & 0.048 & -0.656 & 0.441 & -0.361 \\
\hline 8 & 2 & 1.211 & 0.097 & 1.130 & 1.080 & 12 & 5 & -0.245 & -0.076 & -0.034 & -0.135 \\
\hline 8 & 3 & -0.208 & -0.215 & 0.092 & 0.347 & 12 & 6 & 0.914 & -0.369 & 0.245 & -0.713 \\
\hline 8 & 4 & -0.220 & 0.388 & -0.465 & 0.664 & 12 & 7 & -0.166 & 0.175 & -0.421 & 0.367 \\
\hline 8 & 5 & 0.989 & 0.437 & 0.865 & 0.483 & 12 & 8 & 0.150 & 0.757 & -0.126 & 1.812 \\
\hline 8 & 6 & 0.605 & 1.055 & 0.880 & 2.085 & 12 & 9 & -0.193 & -0.048 & -0.173 & 0.388 \\
\hline 8 & 7 & 0.464 & -0.172 & 0.090 & -0.095 & 12 & 10 & 0.431 & -0.872 & 0.715 & -0.529 \\
\hline 8 & 8 & -0.724 & 0.012 & 0.149 & -0.289 & 12 & 11 & 0.169 & -0.473 & -0.741 & -0.263 \\
\hline & & & & & & 12 & 12 & -0.184 & 0.687 & -0.640 & 1.031 \\
\hline
\end{tabular}




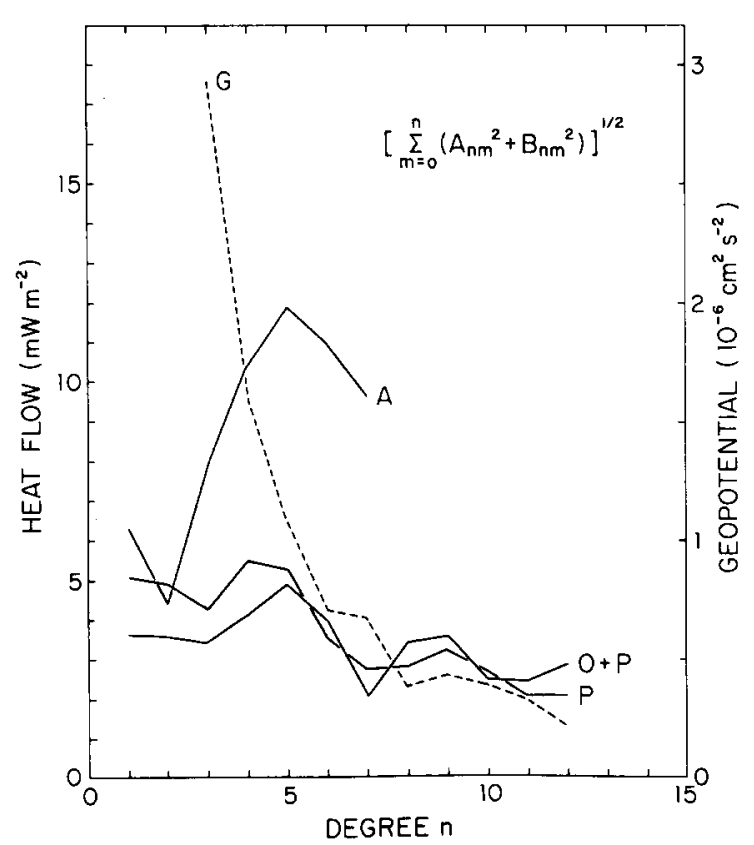

Fig. 8. Comparison of $\mathrm{rms}$ amplitude of all harmonics of degree $n$ : $\mathrm{G}$, for gravitational potential of Gaposchkin and Lambeck [12]; $A$, heat flow observations alone from Horai and Simmons [3];O+P, observed plus predicted heat flow (this paper); $\mathrm{P}$, predicted heat flow alone (this paper).

is shown in Fig. 8 for both degree 12 fields. Mean amplitude spectra calculated in the same manner are included for model $\mathrm{A}$ of the Horai and Simmons heat flow analysis [3] based on observations alone, and for the gravitational potential of Gaposchkin and Lambeck [12]. Our new heat flow spectra decrease gradually and almost monotonically throughout the range $n=1$ to 12 . The substantial difference between the new spectra and those of Horai and Simmons indicates the sensitivity of heat flow spherical harmonics to data in unsurveyed regions of the world. The different shapes of the gravitational potential spectrum and the heat flow spectrum, in particular the relative strength of the higher heat flow harmonics, have been cited [3] as evidence that the sources of regional heat flow variation are to be found relatively shallow in the earth. This difference persists in the new heat flow spectra, although less pronounced than previously observed.

Although our new approach to the global analysis of heat flow yields an improved representation of the heat flow field, we recognize limitations to the meth- od, related to both the predictor and to the spherical harmonic representation. First, the use of a general Polyak-Smirnov-type predictor for continents hides the fact that even though the Mesozoic-Cenozoic distributions of heat flow values are normal in a statistical sense, they may not represent homogeneous populations; the low values having tectonic significance independent of the high values. In the United States, for example, the low heat flow which has been observed for the Late Mesozoic orogenic belt of the Sierra Nevada Mountains is not accounted for by our general predictor, but is of crucial importance in interpreting the tectonic history of the area $[13,14]$. Nor does our predictor make specific use of the important linear heat flow-heat production relationships that are known for some well studied regions. However, the affected areas comprise only a small fraction of the surface of the globe, and furthermore those regions which are known to be anomalous are most likely represented by observations, in which case the predictor is suppressed. A second limitation is the smoothing introduced by the choice of a $5^{\circ} \times 5^{\circ}$ element size and by truncation of the spherical harmonic expansion at degree 12 . The consequence here is that patterns of heat flow variations with half wavelengths much less than $15^{\circ}$, which include important tectono-thermal features such as the Sierra Nevada anomaly discussed above, will not appear in the synthesized representations.

In spite of these limitations, we believe the approach to the global analysis of terrestrial heat flow reported in this paper constitutes a significant improvement in representing the Earth's heat flow field. Furthermore we anticipate that no significant modification to this representation will be required as additional data are obtained. Alteration will be necessary only if the new data prove to be in severe disagreement with our present understanding of the relationship of heat flow to tectonic province and age of ocean floor.

\section{Acknowledgements}

We thank Dr. A.M. Jessop for making available the heat flow data lists before publication. J.H. Sass kindly read the manuscript and offered suggestions for its improvement. This research was partially sup- 
ported by the U.S. National Science Foundation, Earth Science Section. One of us (D.S.C.) held a University of Michigan Rackham Predoctoral Fellowship during the preparation of this paper.

\section{Appendix}

Maps and references used in subdividing $5^{\circ} \times 5^{\circ}$ elements into tectono-thermal and/or oceanic age group regions.

\section{Continents}

Africa: International Tectonic Map of Africa (1968), Association of African Geological Surveys and United Nations Educational Scientific and Cultural Organization, scale $1: 5,000,000$, coordinator G. Choubert .

Antarctica: Geological Map of Antarctica (1971), American Geographical Society, scale $1: 5,000,000$, compiled by C. Craddock.

Australia: Tectonic Map of Australia and New Guinea (1971), Geologic Society of Australia, scale $1: 5,000,000$, Sydney.

Europe and Asia: Tectonic Map of Eurasia (1966), Geological Institute of the Academy of Sciences of the U.S.S.R., scale $1: 5,000,000$, chief editor A.L. Yanshin.

North America: Tectonic Map of North America (1969), United States Geological Survey, scale 1 : 5,000,000, compiled by P.B. King.

South America: Geologic Map of South America (1964), Commission of the Geologic Map of the World, scale 1:5,000,000, general coordinator A.R. Lamego; Tectonic Map of Brazil (1971), Ministry of Mines and Energy, National Department of Mineral Production, Brazil, scale 1:5,000,000, coordinator E.O. Ferreira.

\section{Oceans}

General: Magnetic Lineations of the Oceans (1974), Geological Society of America, compiled by W.C. Pitman III, R.L. Larson, and E.M. Herron. Arctic Ocean: E.M. Herron, J.F. Dewey, and W.C. Pitman III, Plate tectonics model for the evolution of the arctic, Geology 2 (1974) 377-380.

Indian Ocean: D. McKenzie and J.G. Sclater, The Evolution of the Indian Ocean since the Late Creta- ceous, Geophys. J. R. Astron. Soc. 25 (1971) 437-528.

Marginal basins of the Western Pacific: J.G. Sclater, U.G. Ritter, and F.S. Dixon, Heat flow in the southwestern Pacific, J. Geophys. Res. 77 (1972) 5697 5704; J.G. Sclater, Heat flow and elevation of the marginal basins of the western Pacific, J. Geophys. Res. 77 (1972) 5705-5719.

\section{References}

1 W.H.K. Lee and G.J.F. MacDonald, The global variation of terrestrial heat flow, J. Geophys. Res. 68 (1963) 6481-6492.

2 W.H.K. Lee and S. Uyeda, Review of heat flow data, in Terrestrial Heat Flow, Geophysical Monograph Series No. 8 (American Geophysical Union, 1965) 87-190.

3 K. Horai and G. Simmons, Spherical harmonic analysis of terrestrial heat flow, Earth Planet. Sci. Lett. 6 (1969) 386-394.

4 B.G. Polyak and Ya.B. Smirnov, Relationship between terrestrial heat flow and the tectonics of continents, Geotectonics (1968) 205-213.

5 J.G. Sclater and J. Francheteau, The implications of terrestrial heat flow observations on current tectonic and geochemical models of the crust and upper mantle of the earth, Geophys. J. R. Astron. Soc. 20 (1970) $509-542$.

6 A.M. Jessop, J.G. Sclater and M.A. Hobart, World heat flow data collection, Geothermal Series, Earth Physics Branch, Ottawa, in preparation.

7 D. McKenzie and J.G. Sclater, The evolution of the Indian Ocean since Late Cretaceous, Geophys. J. R. Astron. Soc. 25 (1971) 437-528.

8 R.W. Girdler and P. Styles, Two stage Red Sea floor spreading, Nature 247, 5435 (1974) 7-11.

9 D.S. Chapman and H.N. Pollack, Heat flow and incipient rifting in the central African plateau, Nature 256 (1975) $28-30$.

10 W.H.K. Lee, On the global variations of terrestrial heatflow, Phys. Earth Planet. Interiors 2 (1970) 332-341.

11 J.H. Sass, R.J. Monroe and T.H. Moses, Jr., Heat flow from Eastern Panama and Northwestern Columbia, Earth Planet. Sci. Lett. 21 (1974) 134-142.

12 E.M. Gaposchkin and K. Lambeck, 1969 Smithsonian Standard Earth (2), Spec. Rep. 315 (Smithsonian Astrophys. Observ., Cambridge, Mass., 1970) 93 pp.

13 D.D. Blackwell, The Thermal Structure of the Continental Crust, in: The Structure and Physical Properties of the Earth's Crust, Geophysical Monograph Series No. 14 (American Geophysical Union, Washington, 1971) $169-184$.

14 R.F. Roy, D.D. Blackwell and E.R. Decker, Continental Heat Flow, in: The Nature of the Solid Earth, ed. E.C. Robertson (McGraw-Hill, New York, 1972) 506-543. 